\title{
Allozyme-Specific Modification of a Maize Seed Chitinase by a Protein Secreted by the Fungal Pathogen Stenocarpella maydis
}

\author{
Todd A. Naumann and Donald T. Wicklow
}

Bacterial Foodborne Pathogens and Mycology Research Unit, National Center for Agriculture Utilization Research, Peoria, IL 61604. Accepted for publication 12 February 2010.

\begin{abstract}
Naumann, T. A., and Wicklow, D. T. 2010. Allozyme-specific modification of a maize seed chitinase by a protein secreted by the fungal pathogen Stenocarpella maydis. Phytopathology 100:645-654.

Stenocarpella maydis causes both dry-ear rot and stalk rot of maize. Maize inbred lines have varying levels of resistance to ear rot caused by S. maydis. The genetic basis of resistance appears to rely on multiple genetic factors, none of which are known. The commonly used stiff-stalk inbred line B73 has been shown to be strongly susceptible to ear rot caused by $S$. maydis. Here, we report that the ChitA protein alloform from B73, ChitA-F, encoded by a known allele of the chiA gene, is susceptible

presence of both ChitA alloforms in healthy ears, and showed that ChitAF but not ChitA-S was modified in ears rotted by $S$. maydis. The ChitA-F protein was purified from inbred line B73 and ChitA-S from LH82. ChitA-F was modified more efficiently than ChitA-S by $S$. maydis protein extracts in vitro. The chiA gene from LH82 was cloned and sequenced. It is a novel allele that encodes six polymorphisms relative to the known allele from B73. This is the first demonstration that the susceptibility to modification of a fungal targeted plant chitinase differs among inbred lines. These findings suggest that the LH82 chiA allele may be a specific genetic determinant that contributes to resistance to ear rot caused by $S$. maydis whereas the B73 allele may contribute to susceptibility.
\end{abstract} to modification by a protein (Stm-cmp) secreted by $S$. maydis. We also identify a new allele of chiA (from inbred line LH82) which encodes ChitA-S, an alloform of ChitA that is resistant to Stm-cmp modification. Chitinase zymogram analysis of seed from a commercial field showed the
Additional keywords: breeding, chitinase-modifying protein, class IV, Diplodia, disease resistance, zeamatin.
The genus Stenocarpella Syd. \& P. Syd. (teleomorph unknown; Diaporthales) (9) contains two species that cause a dry rot of maize ears: Stenocarpella macrospora (Earle) B. Sutton (syn. Diplodia macrospora Earle) and S. maydis (Berk.) B. Sutton (syn. Diplodia maydis (Berk.) Sacc.). Maize diseases caused by Stenocarpella spp. are worldwide in their distribution. Although $S$. maydis is reported from humid zones wherever corn is grown, $S$. macrospora is most prevalent in humid subtropical and tropical zones where plants exhibiting dry-ear rot and stalk rot may also display symptoms of leaf striping $(18,35)$.

In order to colonize maize ears and produce dry-ear rot, Stenocarpella spp. must overcome defense mechanisms present in the caryopsis. (From this point, we use the term seed, although we are referring to not only the embryo and endosperm but also the entire structure that would more accurately be called the caryopsis). One facet of seed defenses is a group of proteins termed chitinases (13). Chitinases are enzymes (EC 3.2.1.14) that degrade chitin, a polymer of the monosaccharide $\mathrm{N}$-acetyl-glucosamine (GlcNac). Chitin is a component of fungal cell walls. Plant chitinases are thought to defend against fungal invasion either directly, by inhibiting fungal growth (31), or indirectly, by cleaving fungal cell walls to produce small signaling molecules that bind plant receptors, resulting in a defense response $(33,40)$.

Corresponding author: T. A. Naumann;

E-mail address: todd.naumann@ars.usda.gov

Mention of a trade name or commercial products in this publication is solely for the purpose of providing specific information and does not imply recommendation or endorsement by the United States Department of Agriculture.

doi:10.1094/PHYTO-100-7-0645

This article is in the public domain and not copyrightable. It may be freely reprinted with customary crediting of the source. The American Phytopathological Society, 2010
Plant chitinases are divided into classes based on amino acid sequence and predicted structure (22). Plant class IV chitinases are composed of four regions: an amino terminal signal sequence that targets the protein for secretion, a chitin-binding domain that allows the protein to bind insoluble chitin with high affinity, a flexible linker region that separates the chitin-binding domain from the catalytic domain, and the catalytic domain that functions to cleave chitin. The SignalP algorithm predicts that the amino terminal signal sequence is removed by the action of signal peptidase I (4). This results in a mature secreted protein with an amino terminal chitin-binding domain, a flexible linker, and a carboxyl terminal chitinase domain.

Maize seed contain abundant amounts of two class IV chitinases: ChitA and ChitB (16). These chitinases, in purified form, were shown to inhibit the growth of fungi growing on agar plates, but only when tested against certain species. Recently, we reported that ChitA is modified by a secreted protein from Bipolaris zeicola termed chitinase-modifying protein (Bz-cmp) (21). Modification of purified ChitA by purified Bz-cmp reduces its apparent molecular weight when analyzed by sodium dodecyl sulfate polyacrylamide gel electrophoresis (SDS-PAGE). In addition, Bzcmp destroys ChitA's chitin-binding ability while the chitinase activity is intact, indicating that Bz-cmp modifies the chitinbinding domain of ChitA.

We also reported that commercial maize hybrids can produce two different forms of ChitA. These forms could result from either differences in the encoding genes-resulting in proteins with slightly different amino acid sequence-or differences in post-translational processing. Both forms of ChitA are equally susceptible to modification by Bz-cmp (21).

In the course of studying changes in seed chitinase content that result from inoculation with $S$. maydis, we discovered that this fungus also secretes a protein that modifies ChitA; however, it only efficiently modifies one form of ChitA. This finding 
prompted us to determine the difference between the two ChitAs. In this article, we show that they are allozymes-proteins encoded by different alleles of the same gene. In addition, we demonstrate that the previously reported ChitA allozyme is susceptible to modification by the protein secreted by $S$. maydis whereas the newly reported one is resistant. Our results imply that resistance to dry-ear rot caused by $S$. maydis might be genetically linked to the chiA gene.

\section{MATERIALS AND METHODS}

Fungal inoculum and culture conditions. $S$. maydis and $S$. macrospora cultures were obtained from the Agricultural Research Culture Collection, Peoria, IL. Five cultures, as indicated (Table 1), originated from the American Type Culture Collection (ATCC). Others were deposited by D. T. Wicklow after isolation and identification based on conidial micromorphology (34). They include: $S$. maydis NRRL 43670, NRRL 52415, NRRL 53563, NRRL 53565, NRRL 53566, and NRRL 53567 isolated from commercial maize seed produced in Illinois; NRRL 31249 and NRRL 53560 from Indiana; NRRL 13608 (=ATCC 10235) and NRRL 53564 from Kentucky; NRRL 53561 and NRRL 53562 from Nebraska; NRRL 13609 (=ATCC 16438) and NRRL 13615 from the United States; S. macrospora NRRL 13610 (=ATCC 26896) from Costa Rica; NRRL 13611 (=ATCC 42808) from Zambia; and NRRL 13612 (=ATCC 18606) from the United States (Georgia). Culture identities were confirmed by DNA sequencing of the internal transcribed spacer (ITS) region and domains D1 and D2 of the nuclear large subunit (28S) rDNA gene and comparison with sequences in the National Center for Biotechnology Information (NCBI) nonredundant database (1 June 2009) using the BLAST algorithm $(23,41)$. DNA sequencing results were deposited in GenBank; sequence accession numbers are listed in Table 1.

Inoculation of maize ears. Maize ears were wounded by a single inoculation with $S$. maydis NRRL 43670 in the late milk to early dough stage of seed maturity (21 days after midsilk; 22 July 2006) for a commercial maize hybrid (FS 6873RR) grown in Kilbourne, IL. Fungal-penetrated toothpicks were prepared by inoculating potato dextrose agar with $S$. maydis and inserting sterile toothpicks. Following incubation to allow fungal colonization, toothpicks were removed from agar and used for plant inoculation. Twenty ears on plants within a single 7-m length of row were inoculated in the mid-ear region by inserting a single wooden toothpick through the husks and developing seed, as far as the rachis (cob). Following natural dry down in the field (16\% moisture content), ears were hand harvested (21 September 2006) and the visibly diseased seed from each ear were pooled and stored in a freezer at $-7^{\circ} \mathrm{C}$ prior to preparation of protein extracts.

Fungal cultures and fermentation conditions. Stenocarpella isolates were grown as potato dextrose agar slant cultures (14 days, $25^{\circ} \mathrm{C}$ ). A suspension of hyphal cells was prepared from these cultures giving a propagule density of $\approx 4 \times 10^{4} \mathrm{ml}^{-1}$ served as inoculum. Fermentations were carried out in individual $500-\mathrm{ml}$ Erlenmeyer flasks containing $50 \mathrm{~g}$ of whole maize seed. Distilled water $(50 \mathrm{ml})$ was added to each flask, and the contents were soaked overnight before being autoclaved at $15 \mathrm{lb} / \mathrm{in} .^{2}$ for $30 \mathrm{~min}$. Flasks were cooled and inoculated with $100 \mu \mathrm{l}$ of hyphal-spore suspension. Cultures were fermented for 30 days at $25^{\circ} \mathrm{C}$, harvested, and stored frozen at $-80^{\circ} \mathrm{C}$.

Chitinase analysis of maize seed. Protein extracts were prepared from diseased and healthy seed. Seed $(1 \mathrm{~g})$ were soaked for $24 \mathrm{~h}$ at $4{ }^{\circ} \mathrm{C}$, dried, frozen in liquid nitrogen, and ground into a powder. The frozen powder was added to buffer $(80 \mathrm{mM}$ sodium acetate $[\mathrm{pH} 5.2]+1 \mathrm{mM}$ EDTA $+1 \mathrm{mM}$ phenylmethylsulfonyl fluoride) at $4{ }^{\circ} \mathrm{C}$ and mixed. Insoluble material was removed by centrifugation ( $5 \mathrm{~min} ; 14,000 \mathrm{rpm} ; 4^{\circ} \mathrm{C}$ ). Protein concentrations were determined by the dye binding technique of Bradford (6).

The chitinase content of the extracts was determined by denaturing chitinase zymography (38). For each extract and a mixed sample (equal volumes of both extracts were mixed and incubated for $1 \mathrm{~h}$ ), $2 \mu \mathrm{g}$ of total protein was combined with loading dye $(80 \mathrm{mM}$ Tris-Cl $[\mathrm{pH} 6.8]+2 \% \mathrm{SDS}+0.02 \%$ bromophenol blue) and heated for $1 \mathrm{~min}$ at $60^{\circ} \mathrm{C}$. Samples were loaded in a $12 \%$ SDS-PAGE gel ( 85 by 80 by $1.5 \mathrm{~mm}$ [length by width by height]) containing glycol chitin. Proteins were separated by electrophoresis at $150 \mathrm{~V}$ for $2 \mathrm{~h}$. After electrophoresis, the gel was incubated for $16 \mathrm{~h}$ at $25^{\circ} \mathrm{C}$ in refolding buffer $(100 \mathrm{mM}$ sodium acetate $[\mathrm{pH} 5.2]+1 \%$ Triton $\mathrm{X}-100)$. Zymograms were stained with fluorescent brightener 28 and imaged with a Versadoc (Bio-Rad, Hercules, CA). Organic extraction and ultrafiltration treatment of diseased seed extracts were performed as described previously (21).

Purification of maize seed chitinases. ChitA proteins were purified from maize inbred lines B73 and LH82 according to a published method (16). The ChitA proteins were previously

TABLE 1. Stenocarpella maydis and $S$. macrospora strains used in this study

\begin{tabular}{|c|c|c|c|c|}
\hline $\mathrm{NRRL}^{\mathrm{a}}$ & Location & Substrate & GenBank $^{\mathrm{b}}$ & Sample no. ${ }^{\mathrm{c}}$ \\
\hline \multicolumn{5}{|l|}{ S. maydis } \\
\hline 43670 & Cerro Gordo, Illinois & Maize seed & GQ167213 & 1 \\
\hline 52415 & Cerro Gordo, Illinois & Maize seed & GQ167214 & 2 \\
\hline 53563 & Cerro Gordo, Illinois & Maize seed & GQ167215 & 3 \\
\hline 53565 & Kilbourne, Illinois & Maize seed & GQ259129 & 4 \\
\hline 53566 & Kilbourne, Illinois & Maize seed & GQ167216 & 5 \\
\hline 53567 & Kilbourne, Illinois & Maize seed & GQ167217 & 6 \\
\hline 31249 & Indianapolis, Indiana & Maize seed & GQ167218 & 7 \\
\hline 53560 & Rochester, Indiana & Maize seed & GQ167219 & 8 \\
\hline 13608 (=ATCC 10235) & Unreported, Kentucky & Maize & GQ428199 & 9 \\
\hline 53564 & Hopkinsville, Kentucky & Maize seed & GQ167220 & 10 \\
\hline 53561 & Crete, Nebraska & Maize seed & GQ167221 & 11 \\
\hline 53562 & Crete, Nebraska & Maize seed & GQ259130 & 12 \\
\hline 13609 (=ATCC 16438) & Unreported, United States & Maize & GQ167222 & 13 \\
\hline 13615 & Unreported, United States & Maize & GQ167223 & 14 \\
\hline \multicolumn{5}{|l|}{ S. macrospora } \\
\hline 13610 (=ATCC 36896) & Costa Rica & Maize & GQ167224 & 15 \\
\hline $13611\left(=\mathrm{ATCC} 42808 ; \mathrm{MRC}^{143}\right)^{\mathrm{d}}$ & South Africa & Maize & GQ167225 & 16 \\
\hline 13612 (=ATCC 18606) & Georgia, United States & Maize leaf lesion & GQ259128 & 17 \\
\hline
\end{tabular}

a ATCC = American Type Culture Collection.

${ }^{\mathrm{b}}$ GenBank accession number (National Center for Biotechnology Information).

c Sample number in Figure 4.

d MRC number (South African Medical Research Council PROMEC Unit culture collection). 
identified by peptide mass fingerprinting (PMF) (21). In this article, the identity of the other $28-\mathrm{kDa}$ protein, ChitB, and the $25-\mathrm{kDa}$ protein, zeamatin, was determined by PMF. Samples of each protein were taken from an SDS-PAGE gel and submitted for tryptic digest and liquid chromatography tandem mass spectrometry analysis (NextGen Sciences Inc., Ann Arbor, MI). Peptides were identified by Mascot (Matrix Science, London) using the NCBI nonredundant database (5 May 2008). Protein identifications were validated using Scaffold (Proteome Software Inc., Portland, OR).
Cmp activity assays. Secreted proteins were extracted from fermentation culture. For each, $5 \mathrm{~g}$ of culture was thawed and combined with $5 \mathrm{ml}$ of extraction buffer $(10 \mathrm{mM}$ sodium acetate [pH 5.2] $+0.2 \mathrm{mM}$ PMSF $+1 \mathrm{mM}$ EDTA $+2 \mathrm{mM}$ ascorbic acid] in a 50-ml conical tube. Samples were incubated for $30 \mathrm{~min}$ at $4^{\circ} \mathrm{C}$; protein extracts were separated from insoluble material by centrifugation ( $\left.5 \mathrm{~min} ; 14,000 \mathrm{rpm} ; 4^{\circ} \mathrm{C}\right)$. Protein concentrations were determined and all extracts were adjusted to a concentration of protein at $100 \mu \mathrm{g} / \mathrm{ml}$ by addition of buffer.

TABLE 2. Oligonucleotide sequences used in this study

\begin{tabular}{|c|c|c|}
\hline Name & Sequence $\left(5^{\prime}-3^{\prime}\right)$ & Description $^{\mathrm{a}}$ \\
\hline \multicolumn{3}{|c|}{ chiA cloning } \\
\hline Afwd1 & CAGAAGCTTCACCGCAGCAACGAACACGAACCTTGG & chiA 5' UTR with HindIII \\
\hline Arev1 & GTCTCTAGATTTTCGCGAGGGTGCGACGCCGAGCAT & chiA 3' UTR with XbaI \\
\hline \multicolumn{3}{|c|}{ chiB cloning } \\
\hline Bfwd1 & CAGAAGCTTCTGATCTCTATATAAGGGGCGGCAACC & chiB 5' UTR with HindIII \\
\hline Brev1 & GTCTCTAGACGAGGGTGCGATGCGACGCCGAGCACA & $c h i B 3^{\prime}$ UTR with XbaI \\
\hline \multicolumn{3}{|c|}{ Plasmid sequencing } \\
\hline Afwd2 & TTCGCCCATGGCGGGACGGAG & chiA exon 1 forward \\
\hline Arev2 & GCTGATGTAGCAGAAATCTGA & chiA exon 2 reverse \\
\hline Bfwd2 & CTTCTTCGCGCACGCCACGCA & chiB exon 1 forward \\
\hline Brev2 & GATCTCGCTGATGTAGCAGAA & chiB exon 2 reverse \\
\hline $\mathrm{T} 7$ & GTAATACGACTCACTATAGGGC & Vector specific \\
\hline T3 & AАTTAАСССТСАСТАAAGGG & Vector specific \\
\hline \multicolumn{3}{|c|}{ Stenocarpella $28 \mathrm{~S}$ sequencing } \\
\hline 28SFwd & GGAAGTAAAAGTCGTAACAAGG & $28 \mathrm{~S}$ sequencing forward \\
\hline 28SRev & GGTCCGTGTTTCAAGACGG & $28 \mathrm{~S}$ sequencing reverse \\
\hline
\end{tabular}

a UTR = untranslated region.

A

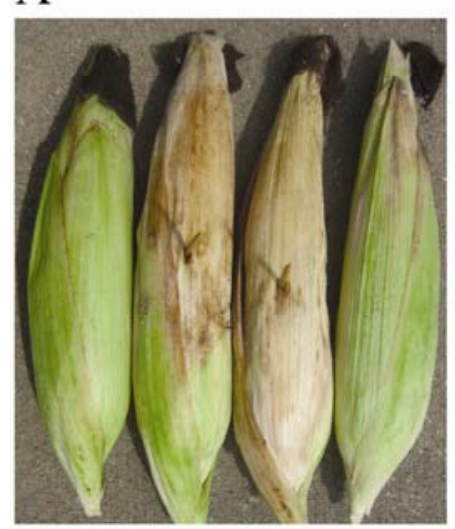

B

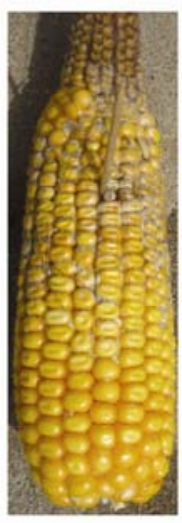

C

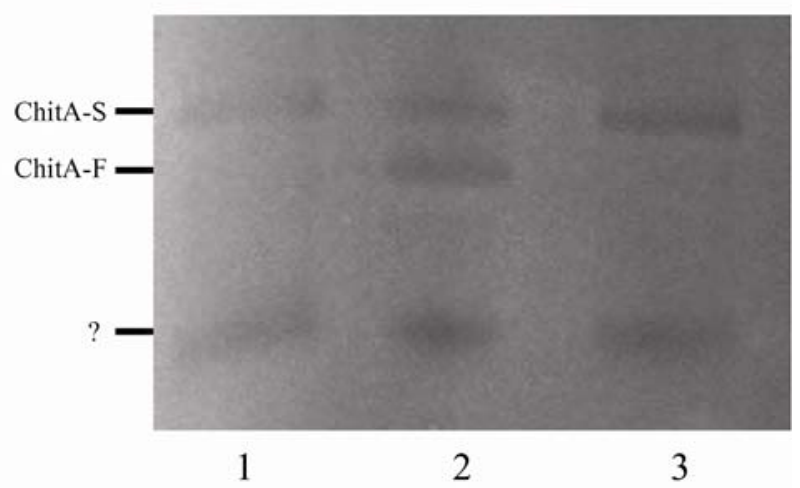

1

\section{D}

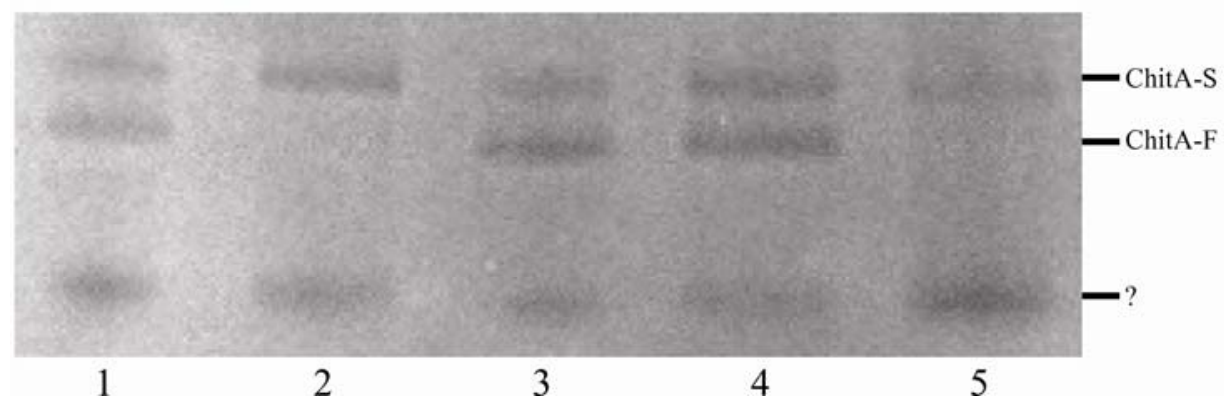

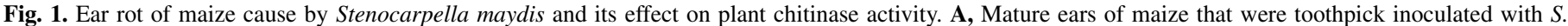

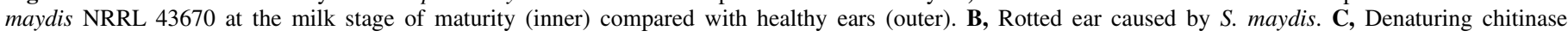

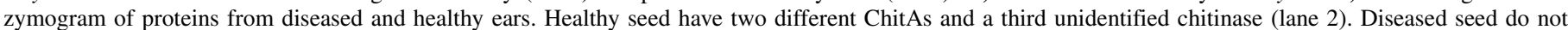

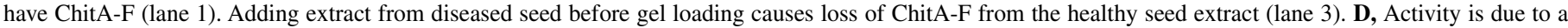

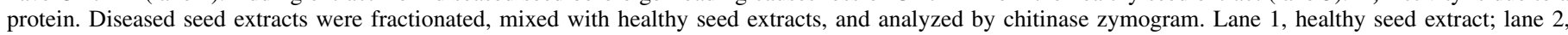

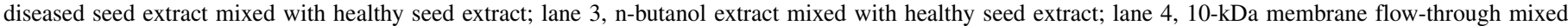

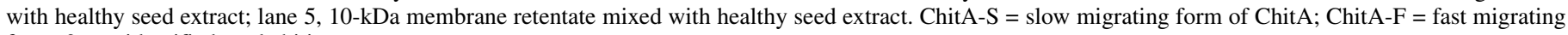
form; ? = unidentified seed chitinase 
Each of the extracts was assayed for cmp activity by incubation with each of the three chitinase substrates. For each reaction, $1 \mu \mathrm{g}$ of secreted proteins was combined with $10 \mu \mathrm{g}$ of purified substrate in a volume of $20 \mu \mathrm{l}$. Reactions were incubated for $16 \mathrm{~h}$ at $25^{\circ} \mathrm{C}$. Products were analyzed by Tricine-SDS-PAGE (12\% T; 3\% C) (29).

Cloning and sequencing of $\boldsymbol{c h i A}$ and $\boldsymbol{c h i B}$ genes. The $\operatorname{chiA}$ and $c h i B$ genes were cloned from genomic DNA of B73 and LH82. Genomic DNA was prepared from leaf tissue of 7-day-old seedlings using the cetyltrimethylammonium bromide procedure (11). Briefly, $1 \mathrm{~g}$ of seedling leaf tissue was combined with liquid nitrogen in a mortar and ground to a powder with a pestle. Genomic DNA was isolated from the powder and resuspended in a final volume of $100 \mu \mathrm{l}$ of Tris-EDTA buffer. The two genes were amplified from each DNA prep by polymerase chain reactin (PCR) using the oligonucleotide primers listed in Table 2 and Platinum Taq DNA polymerase (Invitrogen, Carlsbad, CA) and the following conditions: an initial denaturing step $\left(98^{\circ} \mathrm{C}, 15 \mathrm{~s}\right)$, 35 amplification cycles $\left(96^{\circ} \mathrm{C}, 30 \mathrm{~s} ; 55^{\circ} \mathrm{C}, 45 \mathrm{~s}\right.$; and $\left.72^{\circ} \mathrm{C}, 60 \mathrm{~s}\right)$, and a final extension $\left(72^{\circ} \mathrm{C}, 10 \mathrm{~min}\right)$. PCR products were incubated with restriction endonucleases (EcoRI and $\mathrm{XbaI}$ ) to cleave the oligonucleotide encoded termini. Digested PCR products were then ligated into the pBluescript $\mathrm{KS}(+)$ plasmid (Stratagene, La Jolla, CA), and transformed into Escherichia coli DH5 $\alpha$. The cloned genes were sequenced using the BigDye Terminator v3.1 cycle sequencing kit (Applied Biosystem, Foster City, CA) and a combination of two vector-specific and two internal gene primers. Both strands were sequenced.

The PCR amplification, cloning, and sequencing were repeated three times. In two instances, one of three sequences had a single nucleotide mismatch; it was assumed that this was due to a DNA polymerase error during amplification and the nucleotide in the other two clones was assumed to be correct. The chiA sequence from LH82 is available from GenBank (accession no. GQ856537).

Computational methods. The specificity of the four cloning primers (Afwd1, Arev1, Bfwd1, and Brev1) was confirmed by using the blastN algorithm (2) to search the maize genome for sequences with distant homology (http://www.maizesequence.org/ blast). The novelty of the ChitA sequence from maize inbred line LH82 was confirmed by using the Tblastn (2) algorithm to search both the nonredundant and non-human non-mouse expressed sequence tag databases (5 August 2009) (http:// blast.ncbi.nlm.nih.gov/Blast.cgi). The sequence alignment of ChitA allozymes and ChitB was generated with Clustal W (36). The alignment image was created with the EMBOSS programs emma and showalign (25).

\section{RESULTS}

Stenocarpella ear-rot of maize. To look for changes in maize chitinase activity in response to infection by $S$. maydis, we first
A

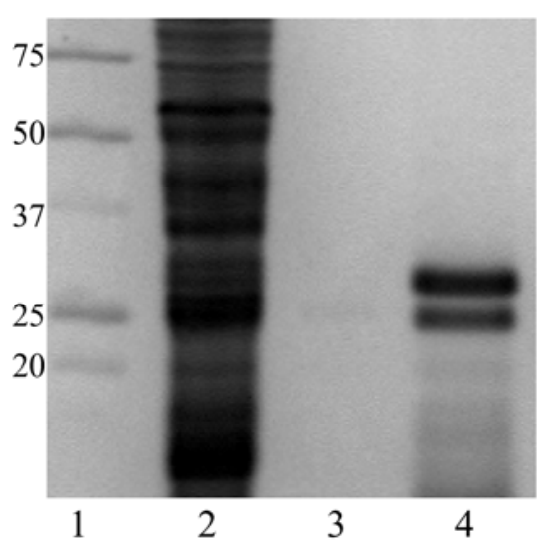

B

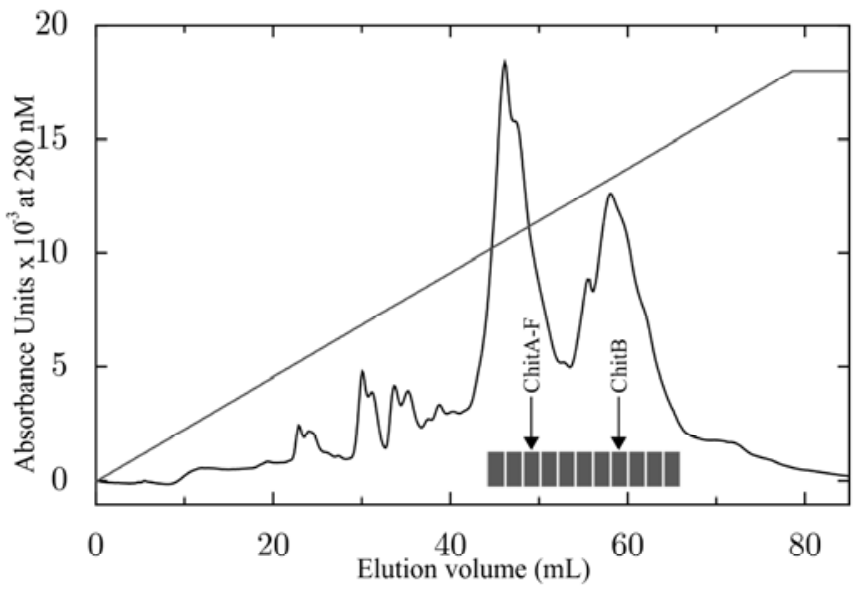

$\mathrm{C}$

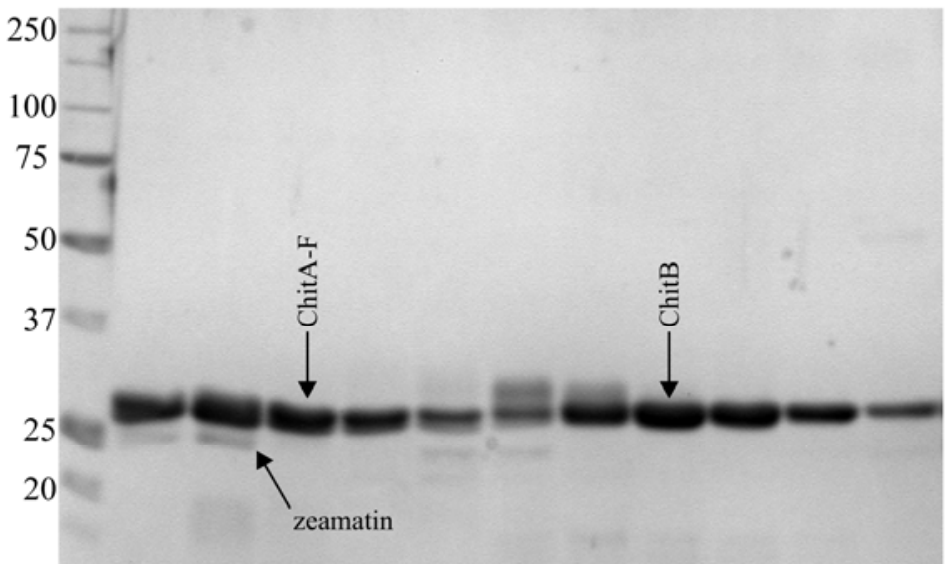

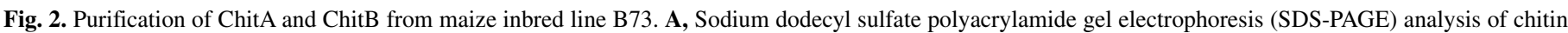

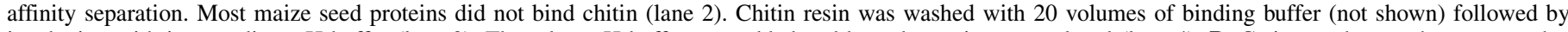

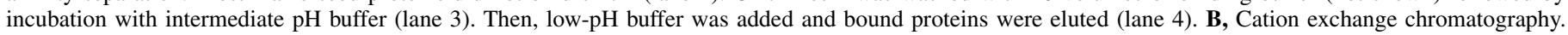

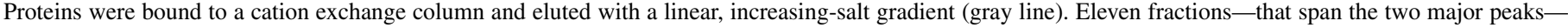

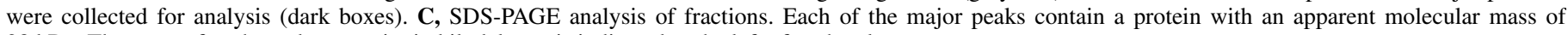
$28 \mathrm{kDa}$. The mass of each marker protein, in kilodaltons, is indicated to the left of each gel. 
generated diseased seed. Ears of maize growing in a commercial field near Kilbourne, IL were inoculated with $S$. maydis NRRL 43670 during early seed development and were harvested at maturity. The inoculated ears had disease symptoms consistent with ear rot caused by $S$. maydis: bleached husks (Fig. 1A); white mycelial growth between seed and cob, incomplete filling of the cob, and evidence of premature seed germination (vivipary) (Fig. 1B).

The chitinase content of the diseased and healthy seed was determined by denaturing chitinase zymography (Fig. 1C). Healthy seed contain three chitinases (lane 2). The top two bands are different forms of the ChitA protein and the bottom band is an unidentified seed chitinase (21). Diseased seed contain two chitinases (lane 1); ChitA-F is absent as a result of $S$. maydis infection. In order to demonstrate that the absence of ChitA-F in diseased seed was due to direct, post-translational modification, healthy and diseased seed extracts were mixed and incubated prior to gel loading. Incubation resulted in loss of ChitA-F from the healthy sample, demonstrating that a molecule produced by $S$. maydis which was still active in the diseased seed extracts was modifying ChitA-F (lane 3).

By fractionating the diseased seed extracts prior to mixing with healthy seed extracts, it was determined that loss of ChitA-F signal was due to a protein (Fig. 1D). When diseased seed extract was mixed with n-butanol, activity did not transfer into the organic phase, as would be expected if activity was due to a small molecule or peptide (lane 3). When passed through a membrane designed to retain proteins $>10 \mathrm{kDa}$, activity was absent in the flow-through (lane 4) and present in the retentate (lane 5). These results indicated that activity was due to a protein $>10 \mathrm{kDa}$, which we named Stm-cmp.

Purification of ChitA-S, ChitA-F, and ChitB. In order to study Stm-cmp activity in vitro, we first purified ChitA-S and ChitA-F. ChitA-S and ChitA-F can be individually purified from maize inbred lines that only contain one of the proteins (21). Seed from maize inbred B73, which is commonly used in producing commercial hybrids and is the genetic model used for sequencing the maize genome, contains ChitA-F but not ChitA-S. ChitA-F was purified from seed by a combination of chitin affinity separation and cation-exchange chromatography (Fig. 2). SDSPAGE analysis of proteins that result from affinity separation showed two protein bands-one with a mass of $28 \mathrm{kDa}$ and a second with a mass of $25 \mathrm{kDa}$ (Fig. 2A, lane 4). Cation exchange chromatography revealed that the $28-\mathrm{kDa}$ band contains two different proteins that elute at different salt concentrations. We previously identified the more weakly bound $28-\mathrm{kDa}$ protein as ChitA (21). In order to identify the other two proteins, we performed PMF on both the $25-\mathrm{kDa}$ protein and the more tightly bound $28-\mathrm{kDa}$ protein (Table 3 ). The $28-\mathrm{kDa}$ protein is ChitB, an isozyme of ChitA that is encoded by a different gene (16); the $25-\mathrm{kDa}$ protein is zeamatin, an antifungal protein found in maize seed that is known to bind $\beta$-1,3-glucans (30).

The purification was repeated with seed from inbred line LH82, which contains ChitA-S but not ChitA-F. Both ChitAs and ChitB appear the same when denatured by addition of SDS, dithiothreitol, and heating at $100^{\circ} \mathrm{C}$ followed by SDS-PAGE separation and protein staining (Fig. 3A). They behave differently when partially denatured by addition of SDS, heated at $60^{\circ} \mathrm{C}$, and assayed for activity in chitinase zymograms (Fig. 3B). ChitA from LH82 produces ChitA-S signal and ChitA from B73 produces

TABLE 3. Peptide mass fingerprinting to identify seed proteins that bind colloidal chitin

\begin{tabular}{lcccc}
\hline Protein & $\begin{array}{c}\text { Unique } \\
\text { peptides }\end{array}$ & $\begin{array}{c}\text { Unique } \\
\text { spectra }\end{array}$ & $\begin{array}{c}\text { Residues } \\
\text { identified }\end{array}$ & $\begin{array}{c}\text { Coverage } \\
(\%)\end{array}$ \\
\hline ChitB & 12 & 18 & $159 / 280$ & 57 \\
Zeamatin & 8 & 10 & $107 / 206$ & 52 \\
\hline
\end{tabular}

ChitA-F; ChitB does not efficiently degrade the substrate. This inability of ChitB to degrade substrate in zymogram gels indicates that it was not detected in zymogram analysis of maize seed. In addition, because its sequence is closely related to that of ChitA, it might also be a substrate of Stm-cmp; therefore, we included it as a third substrate in subsequent cmp reactions.

In vitro cmp activity of proteins secreted by Stenocarpella fermentation cultures. In order to confirm that Stm-cmp activity is commonly present in maize isolates of $S$. maydis, determine the substrate specificity of Stm-cmp in vitro, and determine whether the related maize pathogen $S$. macrospora has cmp activity, we grew fermentation cultures on autoclaved corn and tested them for cmp activity. For each of 17 cultures, an extract of secreted proteins was made and incubated with each of the three maize chitinase substrates. Each reaction was analyzed by SDS-PAGE to determine the amount of cmp activity.

All isolates of $S$. maydis secreted Stm-cmp (Fig. 4). The amount of activity varied and was very low in protein extracts from NRRL 53563 (sample 3) and NRRL 53564 (sample 10). We repeated the experiment, starting with a second set of cultures, and obtained a different set of activity levels, including high amounts of activity in both NRRL 53563 and NRRL 53564 (not shown); therefore, the difference in activity was due to experimental variation rather than isolate-specific differences. Unlike the level of Stm-cmp activity, the preferential modification of ChitA-F relative to ChitA-S did not vary. All of the $S$. maydis protein extracts modified ChitA-F more efficiently than ChitA-S in both experiments. Additionally, ChitB was modified by Stmcmp. Modification of ChitB by Stm-cmp was also more efficient than that of ChitA-S.

The isolates of $S$. macrospora also modified the three proteins (Fig. 4, bottom gel). When compared with the $S$. maydis samples, the level of $\mathrm{cmp}$ activity was lower. Also, the substrate preference was different. NRRL 13610 (sample 15) preferentially modified ChitB while both ChitAs were less
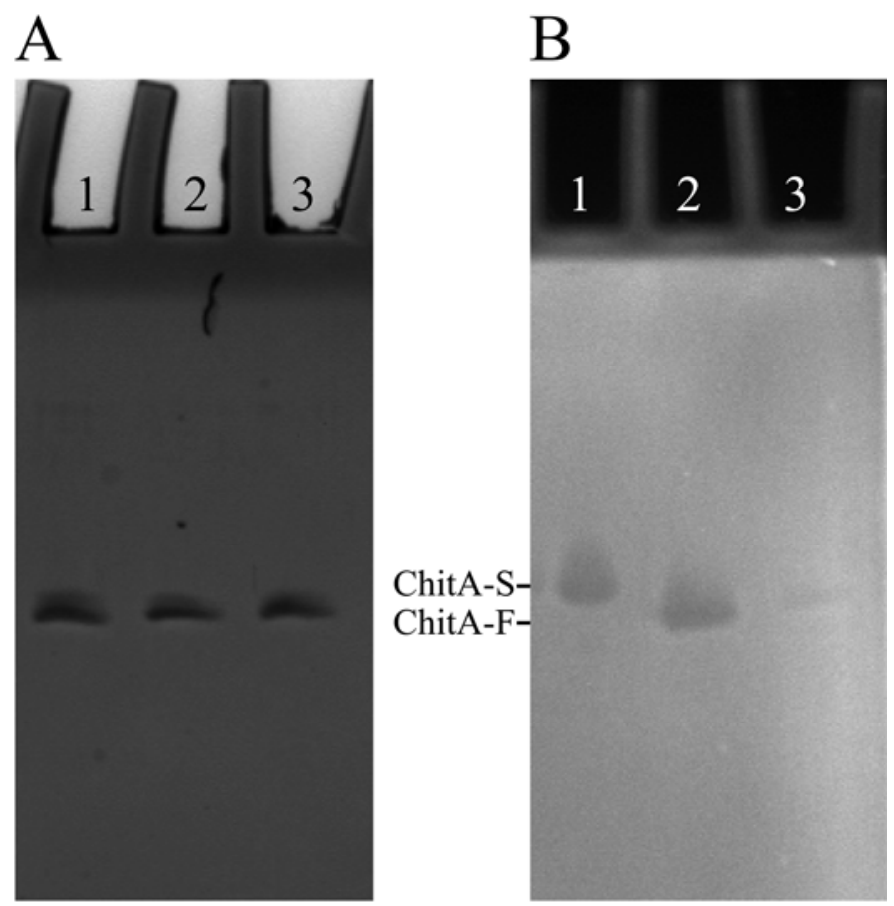

Fig. 3. Polyacrylamide gel analysis of the two purified ChitAs and ChitB. A, Sodium dodecyl sulfate polyacrylamide gel electrophoresis. ChitAs from inbred lines LH82 and B73 and ChitB have equivalent electrophoretic mobility. B, Chitinase zymogram. ChitA from LH82 produces the ChitA-S form while ChitA from B73 produces ChitA-F. ChitB degrades the glycol chitin substrate poorly. Lane $1=$ ChitA purified from inbred line LH82; lane 2 = ChitA from B73; lane $3=$ ChitB from B73. 
efficiently modified. Protein extracts from NRRL 13611 (sample 16) and NRRL 13612 (sample 17) had low cmp activity without substrate preference.

Cloning and DNA sequencing of chiA and chiB. Having observed that ChitA-S is resistant to modification by Stm-cmp in planta and having confirmed the observation with purified proteins in vitro, we wished to determine the difference between the two ChitA proteins. Peptide mass fingerprinting previously demonstrated that, despite their different behavior in chitinase zymogram gels, the proteins are nearly identical and are both produced by the chiA gene (21). The difference in protein behavior could be due to slight differences in amino acid sequence. Maize is diploid and, therefore, has two chiA genes. The two genes could have slightly different DNA sequences (alleles), resulting in production of ChitA proteins with slightly different amino acid sequences (allozymes), as we have observed in commercial hybrids (21; present study). Alternatively, the difference in mature protein could be the result of differences in post-translational processing. In order to determine whether ChitA-S and ChitA-F are produced from identical chiA genes or different alleles, we cloned and sequenced the chiA gene from genomic DNA of the ChitA-Fproducing inbred line B73 and the ChitA-S-producing inbred line LH82. We also cloned and sequenced the ChitB encoding chiB genes.

The cDNA sequences for chiA and $c h i B$ were initially reported by Huynh et al. (16) (GenBank accession nos. M84164 and M84165). Both sequences match genome sequence data reported for inbred line B73 - chiA matches gene GRMZM2G051943 on chromosome 2 and chiB matches GRMZM2G005633 on chromosome 10 (32). Based on the genome sequence, oligonucleotide primers were designed to anneal to the untranslated regions of chiA (Afwd1 and Arev1) and chiB (Bfwd1 and Brev1) (Fig. 5A; Table 2). Genomic DNA was prepared from inbred line B73 and used as a template for PCR reactions. The chiA and chiB genes were PCR amplified, ligated into plasmids, and transformed into E. coli $\mathrm{DH} 5 \alpha$. Gene-containing plasmids were isolated and the genes were sequenced. As expected, both genes matched the reported genome sequence. Then, genomic DNA was prepared from inbred line LH82 and the cloning and sequencing was repeated. The chiB gene matched that of B73; however, the chiA gene sequence was different, indicating that it is a different allele which encodes a different ChitA allozyme (Fig. 5B).

Amino acid sequence analysis of LH82 ChitA. To identify the amino acids that differentiate LH82 and B73 ChitA-and to compare both ChitAs to the ChitB isozyme-we aligned the protein sequences and created an alignment image (Fig. 6). The two ChitAs have six polymorphisms: the secretion signal of LH82 ChitA is one amino acid longer (P1), the chitin-binding domains differ at one amino acid (P2), the linker of LH82 ChitA is three glycine residues shorter (P3), and the chitinase domains have three amino acid differences (P4, P5, and P6). The sequence of ChitB, which is modified by Stm-cmp more efficiently than LH82 ChitA but less efficiently than B73 ChitA, does not match that of either ChitA at P1, P2, or P3; in the chitinase domain, the amino
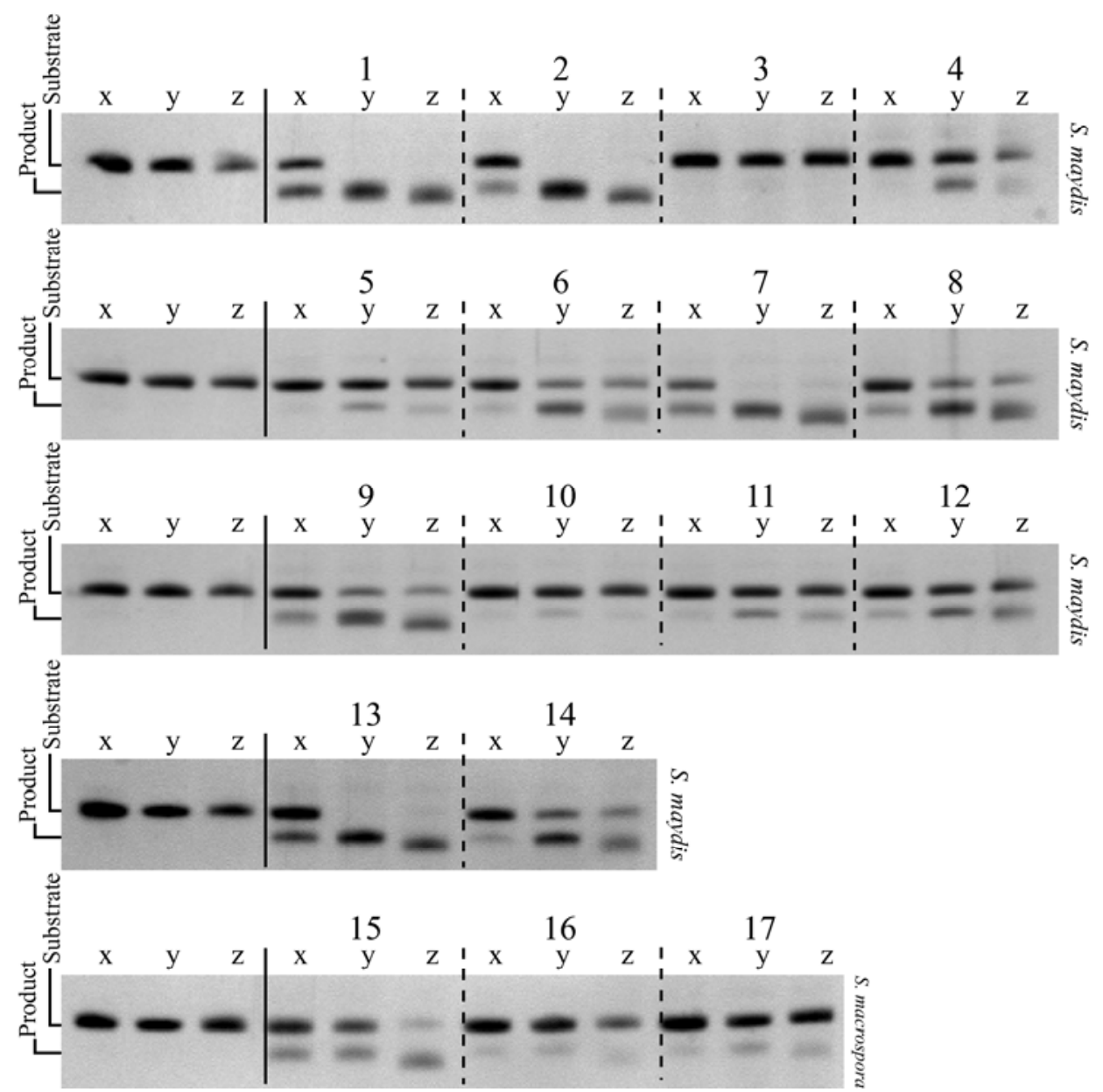

Fig. 4. Chitinase-modifying protein (cmp) assays. Secreted proteins-from 14 maize isolates of Stenocarpella maydis and 3 of $S$. macrospora-were tested for the ability to modify three purified maize chitinases. Purified maize chitinases were incubated with secreted fungal proteins. Reactions were analyzed by sodium dodecyl sulfate polyacrylamide gel electrophoresis; five polyacrylamide gels were used to analyze the 51 reactions. A set of negative controls, purified maize chitinases incubated without addition of fungal protein, was included on each gel (left of solid line). Numbers refer to the fungal isolates listed in Table 1. Letters refer to the purified maize chitinases: $\mathrm{x}=$ ChitA from LH82, $\mathrm{y}=$ ChitA from B73, and $\mathrm{z}=$ ChitB. 
acid sequence of ChitB matches B73 ChitA at all three polymorphic sites.

In order to confirm the novelty of the LH82 ChitA sequence, we searched the NCBI nonredundant database (5 August 2009). Although there weren't any exact matches, a number of ChitA sequences from Zea mays subsp. parviglumis were close. The sequence diversity of ChitA proteins in this annual teosinte, which is the ancestor of modern maize (19), has been studied, and 94 sequences are available from GenBank $(20,37)$. A summary of the Z. mays subsp. parviglumis sequences at each of the maize polymorphic sites is presented in Table 4 .
We also searched for matches of LH82 ChitA to expressed sequence tags. We found one sequence that spans the amino terminal $60 \%$ of the protein sequence and is an exact match: GenBank accession no. FL407643. This sequence is from an expressed sequence tag project that used several hybrids from Pioneer Hi-Bred International, Inc. (Johnston, IA) (1).

\section{DISCUSSION}

Previously, we reported that B. zeicola, a fungal pathogen of maize, secretes a protein called Bz-cmp that modifies two forms

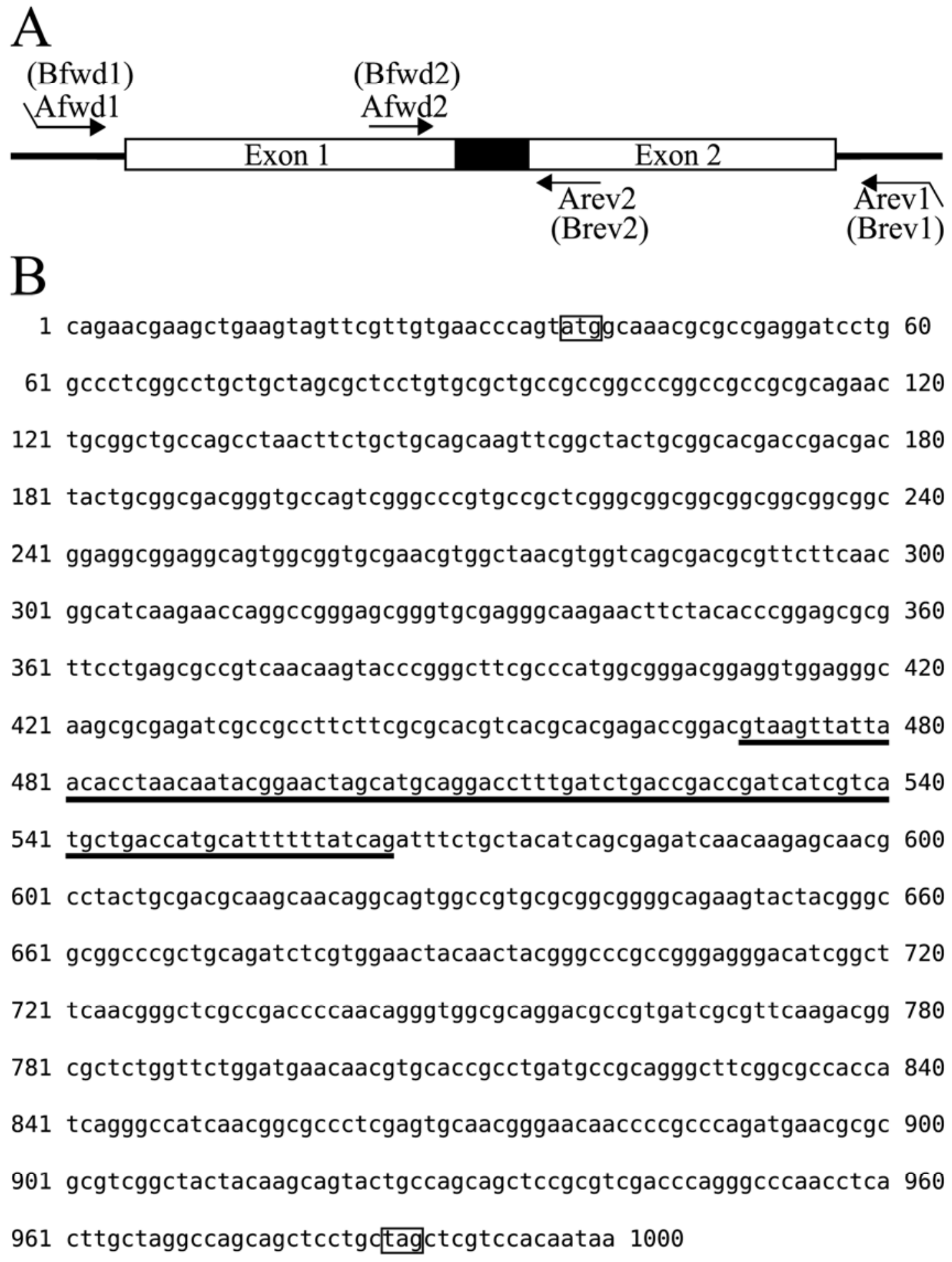

Fig. 5. Cloning and sequencing of chiA and chiB genes. A, Two genes were polymerase chain reaction amplified from genomic DNA of LH82 and B73. Oligonucleotide primers were designed to bind the untranslated region of each gene, with restriction sites added for plasmid cloning. B, chiA gene from LH82, which encodes ChitA-S, is a novel allele. Boxes indicate the start and stop codons, respectively. The intron sequence is underlined. 
of ChitA produced by a commercial maize hybrid (21). In diseased seed, both ChitA proteins were modified. In vitro, purified Bz-cmp modified both ChitA proteins. In this study, we have shown that $S$. maydis secretes a protein, Stm-cmp, that efficiently modifies one of these two forms of ChitA. Zymogram analysis of chitinases from diseased and healthy seed showed that diseased seed lack ChitA-F while ChitA-S is still present. We purified ChitA-F from B73 and ChitA-S from LH82 and tested secreted proteins from $S$. maydis cultures for Stm-cmp activity in vitro and observed that modification of ChitA-F was more efficient than that of ChitA-S. In vitro analysis also showed that the isozyme ChitB is susceptible to Stm-cmp modification. We cloned and sequenced the ChitA-encoding chiA gene from LH82 and found that it is a novel allele; therefore, ChitA-S and ChitA-F are allozymes. Six polymorphisms differentiate the proteins. This is the first demonstration that the susceptibility to modification of a fungal-targeted plant chitinase can vary and is determined by genetic diversity within alleles of a gene.
What is the function of ChitA and ChitB? Maize seed contain large amounts of these class IV chitinases, suggesting that they play a significant role in protecting seed against attack from pathogens during germination (16). The accumulation of ChitA and ChitB during seed maturation may contribute to the increase in resistance to ear rot caused by $S$. maydis that was reported to occur when ears were inoculated 28 days after midsilk (8). $S$. maydis infection of stalk, leaf, and shank tissues is initiated following conidial germination and penetration of epidermal cell walls and host cytoplasm through the formation of an appressorium and enzymatic degradation (5). ChitA might function to inhibit the spread of fungal hyphae, either by degrading fungal cell wall chitin or by releasing chitin elicitors from fungal cell walls to trigger plant defense responses, including production of pathogen response proteins and triggering of the hypersensitive response, a form of programmed cell death that is a major component of plant immunity $(14,17)$. Modification of ChitA to either suppress direct growth inhibition or suppress induction of
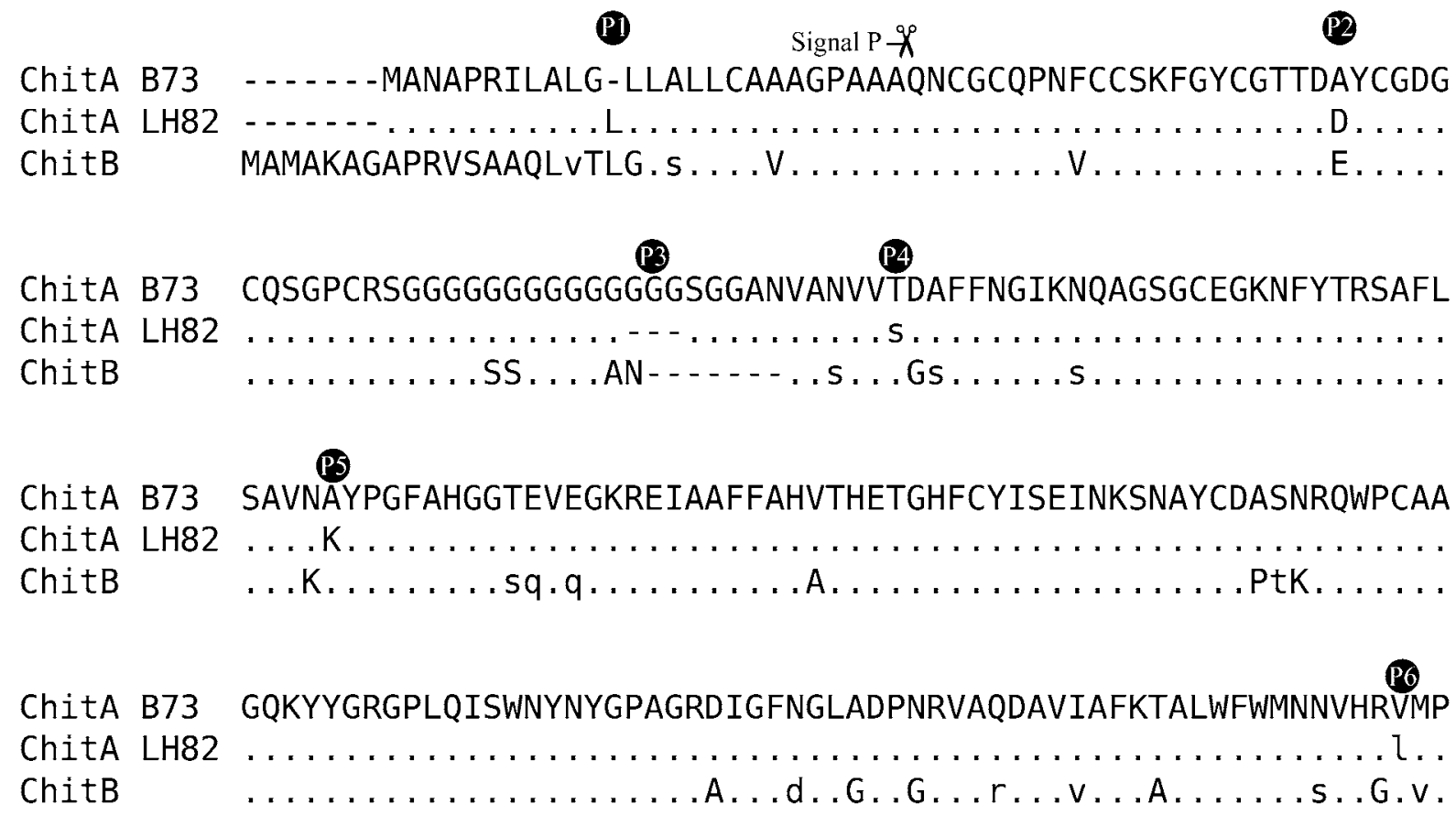

ChitA B73 QGFGATIRAINGALECNGNNPAQMNARVGYYKQYCQQLRVDPGPNLTC

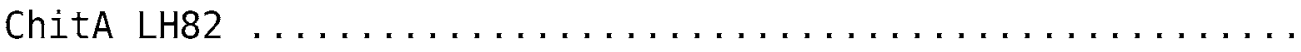

ChitB $\quad \ldots \ldots T \ldots \ldots \ldots, \ldots \ldots \ldots \ldots, \ldots r \ldots, \ldots \ldots \ldots$

Fig. 6. Sequence alignment of ChitAs and ChitB. The ChitA allozymes have six polymorphisms, labeled P1 through P6. The predicted site at which the secretion signal sequence is removed, as determined by the SignalP algorithm, is indicated. The B73 ChitA sequence is shown in the top row and was used as the reference sequence; the LH82 ChitA sequence and ChitB sequence are shown in the second and third rows. Dots indicate homology to the reference sequence. Dashes indicate gaps. Uppercase letters indicate nonconservative amino acid changes. Lowercase letters indicate conservative amino acid changes.

TABLE 4. Number of Zea mays subsp. parviglumis ChitA sequences that match maize inbred line B73 or LH82 at the six polymorphic sites

\begin{tabular}{|c|c|c|c|c|c|c|}
\hline \multirow[b]{2}{*}{ ChitA polymorphism $^{a}$} & \multirow[b]{2}{*}{ ChitA region } & \multicolumn{2}{|c|}{ Peptide sequence $^{b}$} & \multicolumn{3}{|c|}{ Sequences matching ${ }^{c}$} \\
\hline & & LH82 & B73 & LH82 & B73 & Neither \\
\hline $\mathrm{P} 1$ & Secretion signal & $\mathrm{G}(\mathrm{L})_{\underline{3}} \mathrm{~A}$ & $\mathrm{G}(\mathrm{L})_{2} \mathrm{~A}$ & 5 & 70 & 19 \\
\hline $\mathrm{P} 2$ & Chitin-binding domain & TDDYC & TDAYYC & 43 & 51 & 0 \\
\hline P3 & Linker region & $\mathrm{S}(\overline{\mathrm{G}})_{11} \mathrm{~S}$ & $\mathrm{~S}\left(\overline{\mathrm{G})_{14}} \mathrm{~S}\right.$ & 6 & 4 & 84 \\
\hline $\mathrm{P} 4$ & Chitinase domain & VVSDDA & VVTDA & 41 & 52 & 1 \\
\hline P5 & Chitinase domain & VNK̄YP & VNĀYPP & 16 & 78 & 0 \\
\hline P6 & Chitinase domain & HRLMP & HRVMP & 13 & 79 & 2 \\
\hline
\end{tabular}

a Six differences in ChitA sequence from maize inbred lines B73 and LH82 as shown in Figure 6.

${ }^{\mathrm{b}}$ Amino acid sequence at polymorphic sites. Differences are underlined.

c Determined by visual inspection of GenBank sequences in nonredundant database (5 August 2009). 
maize defense responses would promote $S$. maydis endophyticbiotrophic infection.

Stenocarpella spp. are the most important ear rot pathogens in nearly all countries where maize is produced (26). Over several decades, plant pathologists and breeders have offered evidence that maize resistance or susceptibility to $S$. maydis is associated with both qualitatively and quantitatively inherited traits, the former presumably based on single dominant or recessive genes and the latter providing intermediate levels of resistance based on multigenic inheritance. Quantitative resistance to $S$. maydis in which resistance is additively inherited remains the main focus in breeding programs $(10,27,28,39)$. At the same time, dominance gene effects have also contributed to variation in Stenocarpella ear rots of maize $(10,24)$

Although we lack a full understanding of ChitA's biological function, if we assume that $S$. maydis modifies ChitA to facilitate invasion of maize ears, then the chiA allele found in LH82 should contribute to resistance against $S$. maydis (ear rot) and the B73 allele should contribute to susceptibility. Although resistance to ear rot caused by Stenocarpella spp. is reported to be inherited independently from resistance to other ear rot pathogens (15), it can be noted that the proprietary inbred line LH82 was associated with intermediate resistance to both Fusarium graminearum (seedling blight) (12) and Phaeosphaeria maydis (Henn.) Rane, Payak \& Renfro (leaf spot) while inbred lines related to B73 were particularly susceptible (7). Might inbred lines reported to be resistant to Stenocarpella ear rot also possess resistant alleles of chiA? Dorrance and co-workers (10) reported that the public inbred line B73 and its direct descendants are highly susceptible to Stenocarpella ear rot in maize whereas four inbred lines are good sources of resistance. Furthermore, these results were indicative of dominant gene action or epistasis, and agreed with Wiser et al. (42), who had earlier suggested that susceptibility may be dominant over resistance, reporting that crosses between two susceptible parents yielded progeny that were more susceptible than either parent. A high level of susceptibility for inbred line B73 was confirmed by Rossouw et al. (28), who reported that B73 showed pronounced negative specific combining ability in combination with Mo17 and other inbred lines selected as providing resistance in previous resistance evaluations. Dominance gene effects made the major contribution to variation in ear rot of maize caused by $S$. macrospora in the crosses studied using selected maize populations for breeding purposes in the midaltitude $(1,280 \mathrm{~m})$ agroecological zone in Nigeria (24). The evaluation of disease resistance or susceptibility was based on visual assessment of disease severity for individual ears at harvest. The authors concluded that, given the minor contribution of additive effects in resistance to $S$. macrospora, more rapid advances can be made in a breeding program using a method that emphasizes the dominance and epistatic gene effects. Reports identifying maize inbred lines as new sources of resistance to ear rots caused by $S$. maydis $(28,39)$ or $S$. macrospora $(24)$ are based on traditional breeding programs, and no mapping studies of loci conferring resistance to this disease have been carried out (3). Furthermore, no genes have been shown to convey resistance to Stenocarpella ear rot in maize. In the present study, we have identified different alleles of chiA as potential sources of resistance to susceptibility to ear rot caused by $S$. maydis and $S$. macrospora.

\section{LITERATURE CITED}

1. Alexandrov, N., Brover, V., Freidin, S., Toukhan, M., Tatarinova, T., Zhang, H., Swaller, T., Lu, Y., Bouck, J., Flavell, R., and Feldmann, K. 2009. Insights into corn genes derived from large-scale cDNA sequencing. Plant Mol. Biol. 69:179-194.

2. Atschul, S. F., Gish, W., Miller, W., Myers, E. W., and Lipman, D. J. 1990. Basic local alignment search tool. J. Mol. Biol. 215:403-410.

3. Balint-Kurti, P. J., and Johal, G. S. 2009. Maize disease resistance. Pages
229-250 in: Handbook of Maize: Its Biology. J. L. Bennetzen and S. C. Hake, eds. Springer, New York.

4. Bendtsen, J. D., Nielsen, H., von Heijne, G., and Brunak S. 2004. Improved prediction of signal peptides: SignalP 3.0. J. Mol. Biol. 340:783-795.

5. Bensch, M. J., Staden, J., and Rijkenberg, F. H. J. 1992. Time and site of inoculation of maize for optimum infection of ears by Stenocarpella maydis. J. Phytopathol. 136:265-269.

6. Bradford, M. M. 1976. A rapid and sensitive method for the quantitation of microgram quantities of protein utilizing the principle of protein-dye binding. Anal. Biochem. 72:248-254.

7. Carson, M. L. 1999. Vulnerability of U.S. maize germ plasm in Phaeosphaeria leaf spot. Plant Dis. 83:462-464.

8. Chambers, K. R. 1988. Effect of time of inoculation on Diplodia stalk and ear rot of maize in South Africa. Plant Dis. 72:529-531.

9. Crous, P. W., Slippers, B., Wingfield, M. J., Rheeder, J., Marasas, W. F. O., Philips, A. J. L., Alves, A., Burgess, T., Barber, P., and Groenewald, J. Z. 2006. Phylogenetic lineages in the Botryosphaeriaceae. Stud. Mycol. 55:235-253.

10. Dorrance, A. E., Hinkelmann, K. H., and Warren, H. L. 1998. Diallel analysis of Diplodia ear rot resistance in maize. Plant Dis. 82:699-703.

11. Doyle, J. J., and Doyle, J. L. 1987. A rapid DNA isolation procedure for small quantities of fresh leaf tissue. Phytochem. Bull. 19:11-15.

12. DuToit, L. J., Kirby, H. W., and Pedersen, W. L. 1997. Evaluation of an aeroponics system to screen maize genotypes for resistance to Fusarium graminearum seedling blight. Plant Dis. 81:175-179.

13. Gomez, L., Allona, I., Casado, R., and Aragoncillo, C. 2002. Seed chitinases. Seed Sci. Res. 12:217-230.

14. Greenberg, J. T. 1996. Programmed cell death: A way of life for plants. Proc. Natl. Acad. Sci. USA 93:12094-12097.

15. Hooker, A. L. 1956. Association and interspecific aversion in Diplodia. J. Agric. Res. 53:671-680.

16. Huynh, Q., Hironaka, C., Levine, E., Smith, C., Borgmeyer, J., and Shah, D. 1992. Antifungal proteins from plants. Purification, molecular cloning, and antifungal properties of chitinases from maize seed. J. Biol. Chem. 267:6635-6640.

17. Jones, J., and Dangl, J. 2006. The plant immune system. Nature 444:323329.

18. Latterell, F. M., and Rossi, A. E. 1983. Stenocarpella macrospora (= Diplodia macrospora) and $S$. maydis $(=D$. maydis $)$ compared as pathogens of corn. Plant Dis. 67:725-729.

19. Matsuoka, Y., Vigouroux, Y., Goodman, M. M., Sanchez, J. G., Buckler, E., and Doebley, J. 2002. A single domestication for maize shown by multilocus microsatellite genotyping. Proc. Natl. Acad. Sci. USA 99:6080-6084.

20. Moeller, D. A., and Tiffin, P. 2008. Geographic variation in adaptation at the molecular level: A case study of plant immunity genes. Evolution 62:3069-3081

21. Naumann, T., Wicklow, D., and Kendra, D. 2009. Maize seed chitinase is modified by a protein secreted by Bipolaris zeicola. Physiol. Mol. Plant Pathol. 74:134-141.

22. Neuhaus, J., Fritig, B., Linthorst, H., Meins, F., Mikkelsen, J., and Ryals, J. 1996. A revised nomenclature for chitinase genes. Plant Mol. Biol. Rep. 14:102-104.

23. O'Donnell, K. 1996. Progress towards a phylogenetic classification of Fusarium. Sydowia 48:57-70.

24. Olatinwo, R., Cardwell, K., Menkir, A., Deadman, M., and Julian, A. 1999. Inheritance of resistance to Stenocarpella macrospora (Earle) ear rot of maize in the mid-altitude zone of Nigeria. Eur. J. Plant Pathol. 105:535-543.

25. Rice, P., Longden, I., and Bleasby, A. 2000. EMBOSS: The European molecular biology open software suite. Trends Genet. 16:276-277.

26. Rossouw, J. D., Pretorius, Z. A., Silva, H. D., and Lamkey, K. R. 2009. Breeding for resistance to Stenocarpella ear rot in maize. Plant Breed. Rev. 31:223-246.

27. Rossouw, J. D., van Rensburg, J. B. J., and van Deventer, C. S. 2002. Breeding for resistance to ear rot of maize, caused by Stenocarpella maydis (Berk.) Sutton. 1. Evaluation of selection criteria. S. Afr. Tydskr. Plant Grond 19:182-187.

28. Rossouw, J. D., van Rensburg, J. B. J., and van Deventer, C. S. 2002. Breeding for resistance to ear rot of maize, caused by Stenocarpella maydis (Berk.) Sutton. 2. Inheritance of resistance. S. Afr. Tydskr. Plant Grond 19:188-194.

29. Schagger, H. 2006. Tricine-SDS-PAGE. Nat. Protocols 1:16-22.

30. Schimoler-O'Rourke, R., Richardson, M., and Selitrennikoff, C. 2001. Zeamatin inhibits trypsin and $\alpha$-amylase activities. Appl. Environ. Microbiol. 67:2365-2366.

31. Schlumbaum, A., Mauch, F., Vogeli, U., and Boller, T. 1986. Plant chitinases are potent inhibitors of fungal growth. Nature 324:365-367.

32. Schnable, P. S., Ware, D., Fulton, R. S., Stein, J. C., and Wei, F. 2009. The 
B73 maize genome: Complexity, diversity, and dynamics. Science 326:1112-1115.

33. Shibuya, N., and Minami, E. 2001. Oligosaccharide signalling for defence responses in plant. Physiol. Mol. Plant Pathol. 59:223-233.

34. Sutton, B. C. 1980. The Coelomycetes, fungi imperfecti with pycnidia, acervuli and stromata. Commonwealth Mycological Institute, Kew, Surrey, England.

35. Sutton, B. C., and Waterston, J. M. 1966. Diplodia macrospora. In: CMI Descr. Pathog. Fungi Bact. Set 9, No. 83.

36. Thompson, J. D., Higgins, D. G., and Gibson, T. J. 1994. CLUSTAL W: Improving the sensitivity of progressive multiple sequence alignment through sequence weighting, position-specific gap penalties and weight matrix choice. Nucleic Acids Res. 22:4673-4680.

37. Tiffin, P. 2004. Comparative evolutionary histories of chitinase genes in the genus Zea and family Poaceae. Genetics 167:1331-1340.
38. Trudel, J., and Asselin, A. 1989. Detection of chitinase activity after polyacrylamide gel electrophoresis. Anal. Biochem. 178:362-366.

39. van Rensburg, J. B. J., Rossouw, J. D., and van Deventer, C. S. 2003. New generation maize inbred lines resistant to Diplodia ear rot, caused by Stenocarpella maydis (Berk.) Sutton. S. Afr. Plant Soil 20:127-131.

40. Wan, J., Zhang, S., and Stacey, G. 2004. Activation of a mitogen-activated protein kinase pathway in Arabidopsis by chitin. Mol. Plant Pathol. 5:125-135.

41. White, T. J., Bruns, T., Lee, S., and Taylor, J.W. 1990. Amplification and direct sequencing of fungal ribosomal RNA genes for phylogenetics, Pages 315-322 in: PCR Protocols: A Guide to Methods and Applications, M. A. Innis, D. H. Gelfand, J. J. Sninsky, and T. J. White, eds. Academic Press, New York.

42. Wiser, W. J., Kramer, H. H., and Ullstrup, A. J. 1960. Evaluating inbred lines of corn for resistance to Diplodia ear rot. Agron. J. 52:634-626. 